\title{
What's being tested and what's being learnt? A contribution to lessons learned evaluation methods for community-based sustainability initiatives
}

\author{
Andrew MITCHELL, Mark LEMON, Gavin FLETCHER \\ De Montfort University, United Kingdom
}

\begin{abstract}
:
Aim: There is little good practice guidance with respect to methods and skills for conducting lessons learned evaluations of community-based development projects. In this paper we utilise a mixed methods approach to evaluate the lessons learned by the team members and stakeholders of a funded five year "test-and-learn" UK-based sustainability initiative. The approach combines a statistical and a qualitative thematic analysis of transcribed textual data and presents an analytic framework with which to track the lessons learned by community development projects.
\end{abstract}

Design/Research methods: A mixed methods approach combining text and sentiment mining complemented by a qualitative thematic analysis is applied to the same data collected from stakeholder responses to an on-line survey and the transcribed audio recordings of four focus groups in which stakeholders participated.

Conclusions/findings: Employing replicable tools, augmented by qualitative research methods, provide a framework for a systematic approach to elicit and capture lessons learned by a sustainable community development project. These bear on how project activities, from engagement to supporting the local food economy, have been experienced by stakeholders and their learning acquired over the course of the project. Implications for future project design and funding options are considered.

Originality/value of the article: Despite the evident value of its contribution to improving project design and funding options, the evaluation of lessons learned in community-based sustainability work remains under-researched. This paper reflects a double description of the same data through the novel combination of text and sentiment mining techniques with more traditional qualitative thematic analysis, which demonstrates an alternative method of evaluation in this field.

Key words: lessons learned; evaluation; community development; sustainability policy; project management

JEL: R58, Q01, Z18

Correspondence address: Andrew MITCHELL, De Montfort University, Leicester LE1 9BH, United Kingdom. E-mail: p13063976@my365.dmu.ac.uk (Andrew MITCHELL), mlemon@dmu.ac.uk (Mark LEMON), Received: 20.11.2017, Revised: 03.03.2018, Revised: 20.07.2018; Accepted: 22.07.2018 doi: http://dx.doi.org/10.29015/cerem.596 


\section{Introduction}

The modern emphasis on information and its strategic and competitive value as an organisational asset is rooted in the emergence of the knowledge management and organisational studies from the 1980s. Organisational learning (Argyris, Schön 1978; Levitt, March 1988; Schein 1996) and managing knowledge as a resource (Nonaka, Takeuchi 1995; Davenport, Prusak 1998; Boisot 1999) have long since been of strategic concern for organisations (Powell, Bradford 2000; Sutcliffe, Weber 2003; Moustaghfir, Schiuma 2013). It is therefore surprising to discover that as recently as the early 2000s, project experience was still under-utilised as a source of learning for organisations, far less for other projects (Williams 2003). Despite the value of knowledge transfer and learning among projects, to date, there is little good practice guidance available in the Project Management Body of Knowledge (PMBOK) literature to systematically inform the practice of evaluating and capturing project experience in the form of lessons learned.

As a result, the systematic capture of the lessons projects learn rarely actually happens (Duffield, Whitty 2016). If this is the status for large, complex and highinvestment projects (Carrillo et al. 2013; Rolstadås et al. 2014), one may anticipate that the case will be even more pronounced when it comes to capturing the lessons learned from community development type projects that typically involve comparatively smaller budgets with fewer quantifiable objectives.

\subsection{The case for lessons learned}

In an age when project funding is ever more tightly constrained even while the expectations of project funders for projects to deliver on their objectives, on time and to budget continue to increase, there is an evident need for projects to both generate lessons that can be learned from by other projects as well as to acquire the receptivity and capacity themselves to, in turn, learn lessons from predecessors (Love et al. 2016).

For projects deployed to facilitate community learning about strategies for more sustainable living there is an increasing sense of urgency that they are able to articulate and share their experiential learning in order to reduce expending time and 
resources on repeating those practices that have already been shown to be less effective in eliciting pro-sustainability shifts (Makrakis, Kostoulas-Makrakis 2016). To date, this exchange and transfer of learning has tended to be haphazard and sporadic rather than systematic (Newton et al. 2012). Moreover, the expectation of systematically acquiring the lessons learned from project experience is not satisfied by simply undertaking a post-project review (Anbari et al. 2008), despite the prevalence of this approach across different sectors.

This paper attempts to contribute to this sparse literature on methods for eliciting and evaluating lessons learned through the experiences of community development projects. It does so with reference to a community-based sustainability project that was specifically funded to more systematically identify points of learning, and therefore is uniquely suited for exploring the application of a lessons learned evaluation strategy. The evaluative work was commissioned by the Sustainable Harborough Project (SHP) in order to capture the lessons learned over the course of four and a half years of engagement with the town of Market Harborough, Leicestershire, England.

The SHP was one of twelve UK-based BIG Lottery grant-funded communitybased sustainability projects between 2012 to 2017 under the Communities Living Sustainably (CLS) programme (Big Lottery Fund 2012). Each of the twelve funded projects were located in different geological and socio-economic regions in England and covered a mix of rural, semi-urban, and urban communities in efforts to mitigate and adapt to climate change, reduce fuel poverty, optimise the use of local natural and economic opportunities, and to contribute to community sustainability and resilience.

The CLS programme expressed the ideal of making living sustainably easy for people to do, and the programme's emphasis has been explicitly on deriving lessons from that attempt. The emphasis on learning is such that the CLS programme has expected the funded projects to adopt a strategic attitude to testing activities and interventions, and trying to learn from these. Funded projects were expected to experiment with different approaches in order to see what worked, and then to accumulate learning from those experiences. 


\section{Andrew MITCHELL, Mark LEMON, Gavin FLETCHER}

In light of the CLS programme's emphasis on experimentation and learning this paper reports on research undertaken with the SHP staff team, steering Partnership Board and stakeholders to summarise what has been learnt during the course of a "test-and-learn" project. The lessons learned evaluation (LLE) was expressly to track what had been learned from implementing the SHP, to demonstrate the potential for communities to affect change themselves, and to identify approaches and drivers to support locally led approaches.

As a result, this research seeks to explore the value of taking a "test and learn" approach to project development as a source of experiential knowledge to feed forward into the prospective design and funding of future projects. This is to highlight key points of learning, including successful and unsuccessful aspects of governance and decision-making, and to identify those specific relationships associated with the relative success of the project's activities.

\subsection{Evaluating the lessons learned}

A lessons learned process is an evaluation that seeks "to capture the results and experiences from successes, failures and near-misses" for purposes of absorbing these "in to the organisational structure for future use" (McClory et al. 2017: 1322). The temporary character of projects with a customary short-term focus on goals tends to pose a constraint on organisational learning (Bartsch et al. 2013) and this is exacerbated in time-limited projects where knowledge accumulation is dispersed with the dissolution of the project team (Lindner, Wald 2011). Nevertheless, conducting effective lessons learned evaluations is the bread-and-butter of the evaluation profession. As Patton comments, acquiring knowledge "about patterns of program effectiveness allows evaluators to provide guidance about development of new initiatives, policies, and strategies for implementation" (Patton 2001: 333).

A lessons learned evaluation therefore potentially mitigates a primary cause of subsequent project failures that has been attributed to the lack of recommendations for future project design and implementation in the final reports of projects that are terminating (McClory et al. 2017). Indeed, Patton (2001) reviewed cluster evaluation reports funded by the Kellogg Foundation, and found that the ubiquitous reference to "lessons learned" and "best practices" rendered such terms meaningless, 
suggesting that in the evaluation profession, there is a gap in the development of guidelines for good practice lessons learned evaluations. Project learning is an asset, but despite the added value of LLE, with few exceptions (e.g., Thomas 2015), there is still a paucity of good practice guidance in the PMBOK literature on conducting effective LLEs, which may contribute to questioning LLE's effectiveness in disseminating new knowledge for process improvements (Carrillo et al. 2013).

Although Patton (2001) does offer some suggestions for developing what he terms "high-quality lessons learned", fundamentally these guides hinge on a strongly triangulated evidence base. He elaborates this by noting that, with a higher "number of supporting sources for a "lesson learned", the more rigorous the supporting evidence, and the greater the triangulation of supporting sources", then the greater the level of "confidence one has in the significance and meaningfulness of a lesson learned" (2001: 335, original emphases). Above all else then, what constitutes significance in the evaluation of lessons learned is the rigour of the triangulation among a robust evidence base. To date, Patton's advice is the closest the profession appears to come to a set of guidelines for conducting good practice lessons learned evaluations.

The evaluation reported in this paper attempted to optimise the utility for the stakeholders who had commissioned the work (Patton 1997). Consequently, the evaluation deferred to the opinions and reflections of the project staff team, Partnership Board members, and involved community stakeholders as the knowledgeable (i.e., expert) informants about what was important and what was noteworthy with respect to the learning that had been acquired over the course of the project's duration.

This approach is reflected in the data collection method that involved interviewing project staff about the range of project-based activities and work streams underway, their status and the measures of success relative to objectives, and capturing the input of all project and community-based stakeholders through an anonymised on-line survey and four focus groups.

The paper is structured as follows. In the next section, the method for approaching this evaluative research is discussed. Section 3 introduces and discusses the evaluation framework, which comprises: Project team interviews; stakeholder 
survey and focus groups, and the computational analyses of both; the thematic analysis of focus group transcripts; and triangulation meetings. Section 4 considers the evaluation methodology employed, and the paper closes with some conclusions and implications for future lessons learned project evaluation.

It is important to note that the focus of this paper is on supporting a more systematic and replicable evaluation process; a summary of the data and substantive examples will be drawn from the Sustainable Harborough project but it is not our aim to provide an in depth analysis of it. Rather the objective is to learn about the process of evaluation from that reflection. Put differently, the emphasis in this paper is to not only to undertake the evaluation but also to evaluate the method of the evaluation.

\section{Method}

\subsection{Overview of the approach to evaluation}

The evaluation began with a scoping meeting with the Sustainable Harborough Project (SHP) team to identify priorities and clarify expectations, to scope out the project activities along with their perceived status and to elicit whether they had been successful, unsuccessful or inconclusive in their outcomes. A list of relevant stakeholders was identified, the method of research to be followed was agreed and a plan of work outlined.

The next stage involved a review of available project related documents. This primarily focused on official reports, including papers for the quarterly Partnership Board meetings and the end of year progress and accountability reports to BIG Lottery.

Following this, an on-line survey was designed, incorporating feedback from the Project team, and due to the time constraints of the evaluation contract, was hosted for four weeks using an independent Survey Monkey account. Stakeholders were invited to respond to the survey, and participation was not incentivised.

The survey responses were analysed and key themes identified which were developed into focus group prompts. Stakeholders were invited to select their 
preferred date and time to participate in one of four focus groups. Participants in the groups consented to the discussions being audio recorded, and were assured of confidentiality and the anonymity of specific comments. No citations have been attributed to any individual or to any one of the four groups.

The audio recorded focus groups were transcribed in near verbatim fashion, excluding usual conversational stops, pauses, and cross-talk while preserving wordfor-word utterances wherever possible. In conjunction with the survey responses, the focus group transcripts are the primary data source for the subsequent analysis and evaluation.

The transcripts, and open text survey responses were analysed in two iterations. The first used a text mining approach, which treats text statistically, and the second involved a qualitative thematic analysis. Text mining is used here as a tool with which to map out the conversational trends and focal points from the transcripts. Text mining has increasingly been used in medical and business applications to extract structured knowledge from documents which are in unstructured formats (Ur-Rahman, Harding 2012; Kumar, Ravi 2016; Meaney et al. 2016).

The technique of text mining has also been applied to facilitate the detection and exploration of emerging topics and technologies, for example in the domain of forecasting (Kayser, Blind 2017). It is therefore an appropriate tool with which to statistically parse unstructured data in order to map emergent structures and meanings implicit in the text, and this is how it has been used here. Text mining is a powerful technique which helps to reveal word use patterns which are strongly associated with the predominant concerns and opinions expressed by the authors of the text, in this case the focus group participants and survey respondents.

The text mining was supplemented with a sentiment analysis, which uses the NRC lexicon of affective terms (Saif et al. 2012; Mohammad, Turney 2013), and returns a bar graph of the content of text according to eight emotional parameters. The benefit of this approach is that it enables the analysis to get at the emotional or attitudinal base of text, shows the overall opinion of respondents to the focus of the questions and is indicative of their general mood as expressed through word use.

Finally, the analysis was triangulated in consultation with the Project team as a form of "sanity" check. This basically involved testing whether the analysis made 


\section{Andrew MITCHELL, Mark LEMON, Gavin FLETCHER}

sense to the Project team, highlighting anything that may have been unexpected, and identifying any gaps in the analysis. The last stage in the process was a submitted report and summary presentation given to the Partnership Board.

\subsection{Preparation of data for text mining:}

A few words are warranted to explain how the textual data were managed and prepared for the statistical textual analysis. In text mining applications, passages of text are broken down into single words or "tokens" and it is the statistical relationship between tokens that is the focus of analysis. The analysis returns the frequency of word usage as well as the strength of associations among key terms in context. Text is unstructured data however, and requires pre-processing which converts raw text into a matrix format.

The source text files were reviewed using a find-and-replace text editor function, and permutations among words were systematically reduced. For example, multi-word names have been converted into acronyms - "Farm Community Garden" (or its variants "Farm Garden", "Community Garden" and "Farm Community Garden", etc.) were compressed into the single acronym "FCG" to preserve the meaning of the individual words used to collectively refer to something specifically: the community growing project at a local farm. This process was repeated for all multi-worded activities or outputs and organisations referred to in both the survey responses and the focus group transcripts.

The cleaned text files were read into the text-mining ("tm") package (Feinerer et al. 2008; Feinerer, Hornik 2014), a text mining function written for the statistical and programming platform R (R Core Team 2014), and the package libraries were used to standardise the tokens. This involves removing punctuation marks, converting all letters to lower case, and removing common words that facilitate speech but which have negligible discriminatory value. The latter are "stop-words" and are ubiquitous in spoken and written speech, and include "and", "the", "a", "an", "or", etc. Finally, words are stemmed, which converts all variations on a word stem to its lemma, such that "improv" refers to "improve", "improvement", "improved", as well as "improving", which reduces "noise". 
In this way pre-processing converts bodies of text into bags-of-words, wherein rarely occurring (sparse) terms are assumed to hold limited predictive power. Following data pre-processing, the data are parsed by the Document Term Matrix function which constructs a matrix of terms as columns and unique word occurrence frequencies as a row.

In addition to the text mining, a sentiment analysis, or opinion mining, was carried out, using the R "syuzhet" package (Jockers 2017), which references the NRC Lexicon of affective terms (Saif et al. 2012; Mohammad, Turney 2013).

Taken together, the text mining and sentiment analysis of the focus group transcriptions offers statistical and affective insight into the implicit structure of stakeholder reflections on project learning about eliciting community sustainability.

\subsection{Thematic analysis}

The second iteration analyses the transcribed contributions of focus group participants in a way that preserves the coherence of the whole corpus as a repository of meaning and sensibility. Words are used in coherent strings which generate meaning in their own right. This is the exact opposite of the text mining approach which disregards the meanings of words as they are used in relation to each other.

The process of thematic analysis involves reviewing the text several times and generating codes that describe what emerge as themes in the text (Braun, Clarke 2006; Rennie 2012). The occurrence of these themes is coded systematically, and the codes, over several iterations, are examined for what the referenced texts share in common. This review of the data gives rise to code categories which are metadescriptions of the unifying thematic of text clusters across and within individual text files. The practice of thematic analysis is to bring latent narrative threads to the surface in terms of landscapes of consciousness and of action (Bruner 1986).

The identification and highlighting of narrative themes is a means of extracting meanings from the text (Braun, Clarke 2006), and these may take the form of contradictions and exceptions to the dominant narrative, alternate perspectives and interpretations of the same set of events, gaps and opportunities for action that weren't initially apparent, and so on (Bryman 2012). 
This type of qualitative analysis returns narratives which can be traced as traversing the text, as sub-texts and meta-themes. These are akin to plot lines and story arcs, and highlighting these adds a richer texture than may be apparent from an initial reading of the dominant text.

\section{A framework for lessons learned evaluation:}

Complex and dynamic community development projects are informed by diverse approaches to project management, work with and through a diverse range of professional and volunteer stakeholders, and are unlikely to operate with structured project management frameworks, such as PRINCE2 (Office of Government Commerce [OGC] 2009). As a result, efforts to capture lessons learned are likely to be even more heterogeneous than in projects that do operate with such structured governance standards.

In order to optimise eliciting, capturing and benefiting from the lessons learned by community development projects, we developed and applied a systematic methodological framework, consisting of four component processes, as discussed in this section. These are applied sequentially, beginning with a scoping interview with the commissioning Project staff team, the development and analysis of an on-line survey with stakeholders, the facilitation of four stakeholder focus groups, the content of which was analysed using quantitative text mining and sentiment analysis, as well as qualitative thematic analysis, and concluding with a triangulation meeting with the Project team and Partnership Board to present and review the findings.

\subsection{Case study overview}

As noted earlier, the Sustainable Harborough Project (SHP) was a fully-funded five year initiative under the UK's BIG Lottery's Communities Living Sustainably test-and-learn project, which was intended to generate good practice in the domain. In this instance, SHP was funded to deliver against six outcomes, supported by a 
range of performance indicators. Table 1, summarises the outcomes and indicator framework for SHP.

Table 1. SHP Outcomes and Indicator framework (RCC-L 2012)

\begin{tabular}{|c|c|}
\hline Outcomes & Indicators \\
\hline $\begin{array}{l}\text { 1) Improve knowledge and skills } \\
\text { on sustainable living amongst the } \\
\text { local community, and increase } \\
\text { public support and participation in } \\
\text { activities to improve local } \\
\text { sustainability }\end{array}$ & $\begin{array}{l}\text { 1a: Number of people participating as volunteers, etc. } \\
\text { 1b: Number of people reporting improved knowledge/ skills }\end{array}$ \\
\hline $\begin{array}{l}\text { 2) Bring about practical action and } \\
\text { behaviour change to reduce the } \\
\text { environmental impact and carbon } \\
\text { emissions of local households, } \\
\text { businesses and schools }\end{array}$ & $\begin{array}{l}\text { 2a: Reduction in } \mathrm{CO} 2 \text { emissions due to energy use in } \mathrm{MH} \\
\text { 2b: Reduction in } \mathrm{CO} 2 \text { emissions per yr due to project } \\
\text { 2c: Number of interventions carried out by households } \\
\text { 2d: Number of interventions carried out by businesses } \\
\text { 2e: Number of interventions carried out by schools }\end{array}$ \\
\hline $\begin{array}{l}\text { 3) Increase the resilience of the } \\
\text { local community to environmental } \\
\text { change, through increased } \\
\text { community use of local natural } \\
\text { resources and assistance for } \\
\text { vulnerable people to manage } \\
\text { changes in the local environment } \\
\text { and increasing food and fuel costs. }\end{array}$ & $\begin{array}{l}\text { 3a: Economic value of local natural resources used per year in } \\
\text { Market Harborough ( }+5 \text { mile radius) } \\
\text { 3b: Number of vulnerable individuals and households with } \\
\text { reduced food and fuel costs }\end{array}$ \\
\hline $\begin{array}{l}\text { 4) Establish local enterprises that } \\
\text { harness local resources and } \\
\text { increase local trade to sustain and } \\
\text { develop the local economy. }\end{array}$ & $\begin{array}{l}\text { 4a: Increased value of local trade due to project } \\
4 \mathrm{~b} \text { : Number of new community enterprises }\end{array}$ \\
\hline $\begin{array}{l}\text { 5) Preserve and improve } \\
\text { biodiversity throughout the } \\
\text { community, including public and } \\
\text { private spaces and the River } \\
\text { Welland. }\end{array}$ & 5a: Increase in number of bees counted on buzzing borders \\
\hline $\begin{array}{l}\text { 6) Improve and disseminate } \\
\text { knowledge across UK communities } \\
\text { on how to improve sustainability in } \\
\text { an average-sized UK market town, } \\
\text { targeting Market Towns in } \\
\text { particular }\end{array}$ & $\begin{array}{l}\text { 6a: Number of people from other communities reached via } \\
\text { dissemination activities } \\
\text { 6b: Number of public reports produced describing learning } \\
\text { from project }\end{array}$ \\
\hline
\end{tabular}


The project is located in Market Harborough, a market town in a semi-rural area of predominantly livestock farming of south-east Leicestershire about $140 \mathrm{~km}$ north of London. The town has a population of almost 23,000 according to the 2011 census, and is generally considered relatively affluent and a desirable place to live. While the town is the seat for the Conservative-led district council, it has no town parish with governance responsibilities.

\subsection{Project team interviews}

During the initial scoping meeting for this evaluation with the Sustainable Harborough Project team in May 2017, the team were asked to generate a list of all the activities ${ }^{1}$ the Project had instigated. This generated 165 unique activities which were ordered into themes, such as energy-related, food-related, etc. A number of activities were grouped under several themes, for example one activity was classified as food-related and capacity building as well as biodiversity related (e.g., growing organic food crops in a local plot under the supervision and guidance of Master Gardeners). It should also be noted that although referred to generically as "activities", this description covers a range of undertakings of differing scales and levels of complexity, from one-off public-facing events to on-going practices of building capacity in the local food and drink economy. For example, of the 65 activities identified as pertaining to energy-related work, 54 (83\%) were also were classified under the capacity-building theme.

The results of this activity analysis are shown in Figure 1 which groups the activities by theme and relative proportion of all Project activities. Proportionately more activities were energy related; these also tended to be more technologically challenging and most subject to national and regional policy governance frameworks.

\footnotetext{
${ }^{1}$ A distinction is drawn here between "project", which refers to the Sustainable Harborough Project as an entity, which is realised through a range of "activities" which are the actions, behaviours, processes and groups that the project has set in motion and/ or contributes to its continuance. The range of activities also vary considerably in terms of complexity, scope, scale, and the amount of engagement with local, regional, and national policy frameworks. Energy-related activities, for example, tend to be more complex, technical and constrained by policy frameworks, whereas capacity building activities are significantly more flexible, straight forward, and require less consideration of policy.
} 
Once sorted in this way, activities were classified according to the degree of success associated with the relevant outcomes in terms of the activities' objective (i.e., successful, unsuccessful, or indeterminate because they had yet to complete). Finally, activities were also classified in terms of whether the active was pending, active, complete, or dropped. Therefore, if an activity was assessed as being of indeterminate success, that activity would also be classified as "active" or "pending".

From Table 1, it is apparent that the Project was involved in a range of activities converging around four themes: energy-related activities (including mitigating greenhouse gas emissions), the promotion of local natural resources, expressed through locally sourced food and drink supply chains, supporting biodiversity, and contributing to local capacity building.

Table 2. Project activity analysis

\begin{tabular}{|l|c|c|c|c|}
\hline \multicolumn{1}{|c|}{$n$} & $\begin{array}{c}\text { Energy- } \\
\text { Related }\end{array}$ & Food-Related & Biodiversity & Capacity Building \\
\hline $\begin{array}{l}\text { Capacity Building } \\
(\%)\end{array}$ & $54(83.01 \%)$ & $37(77.01 \%)$ & $11(61.11 \%)$ & $34(25.19 \%)$ \\
\hline Successful & $36(55.38 \%)$ & $36(75.00 \%)$ & $14(77.78 \%)$ & $31(91.18 \%)$ \\
\hline Unsuccessful & $15(23.08 \%)$ & $7(14.58 \%)$ & $2(11.11 \%)$ & $2(5.88 \%)$ \\
\hline Undetermined & $14(21.54 \%)$ & $5(10.42 \%)$ & $2(11.11 \%)$ & $1(2.94 \%)$ \\
\hline Active & $22(33.85 \%)$ & $22(45.83 \%)$ & $9(50.00 \%)$ & $11(32.35 \%)$ \\
\hline Dropped & $13(20.00 \%)$ & $4(8.33 \%)$ & $1(5.56 \%)$ & $1(2.94 \%)$ \\
\hline Pending & $5(7.69 \%)$ & $3(6.25 \%)$ & $1(5.56 \%)$ & 0 \\
\hline Completed & $21(32.30 \%)$ & $19(39.58 \%)$ & $7(38.89 \%)$ & $22(64.71 \%)$ \\
\hline
\end{tabular}

Source: authors' own elaboration ${ }^{2}$.

Table 2 above, summarises the Project team's breakdown of activity across these themes. These activities are summarised in Figures 1 and 2 in terms of the

\footnotetext{
${ }^{2}$ The first author was commissioned by the Project to conduct a discrete piece of research into the lessons learned by the Project over the course of its five years of operation. The findings were intended to feed forward into the summative review of the Project which would be undertaken independently by another contractor.
} 


\section{Andrew MITCHELL, Mark LEMON, Gavin FLETCHER}

assessment of relative successes and the delivery status of the activities, respectively.

\section{Figure 1. Successes across activity themes as reported by Project staff team}

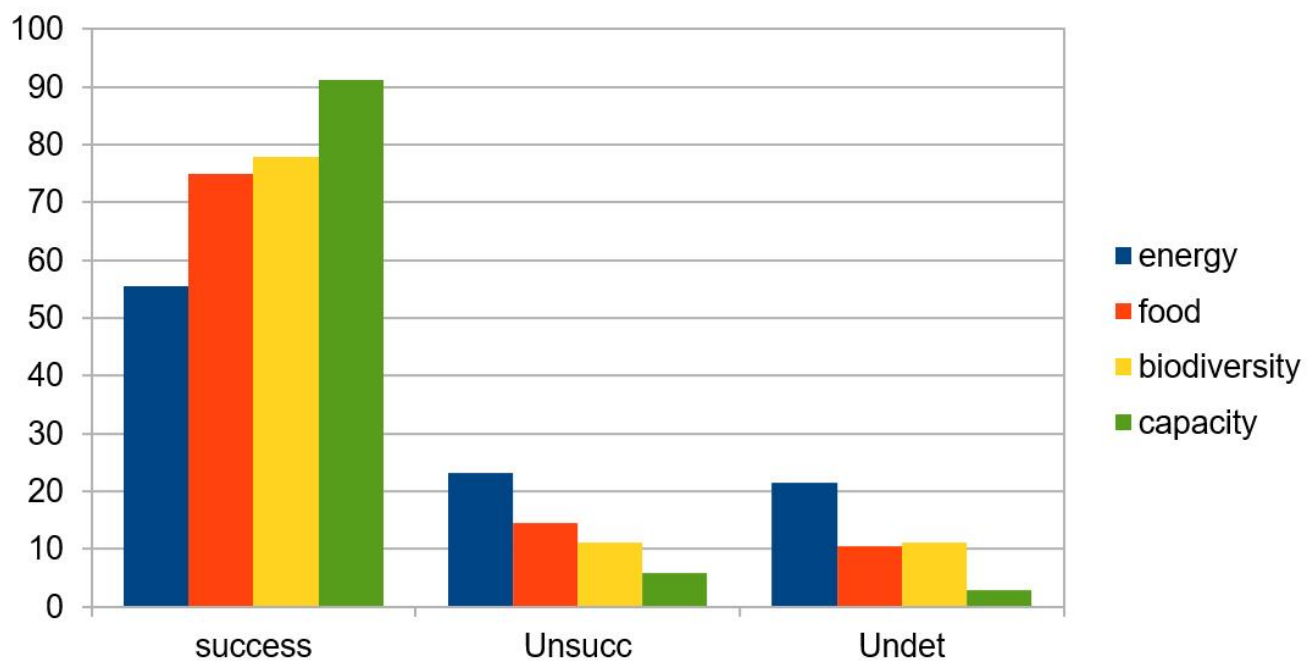

"Unsucc" refers to unsuccessful; "Undet" refers to "undetermined".

Source: authors' own elaboration.

It is evident that capacity-building activities were considered by the Project team as the most successful of the four activities, with biodiversity and food-related activities coming in second and third place respectively. Energy-related activities are considered the least successful activities, although they are those which are also most likely to be classified as pending clear outcomes, as illustrated in Figure 2. This shows the same four activity themes but this time in terms of their delivery status.

The activities which have been completed tend to be those related to capacitybuilding, while energy-related activities show a relatively low completion rate and a correspondingly high rate of being dropped or pending completion. When the activity themes are compared with respect to their active status, more biodiversity and food-related project activities are classed as active (or current), followed by energy and capacity related activities respectively. 


\section{Figure 2. Delivery status across activity themes}

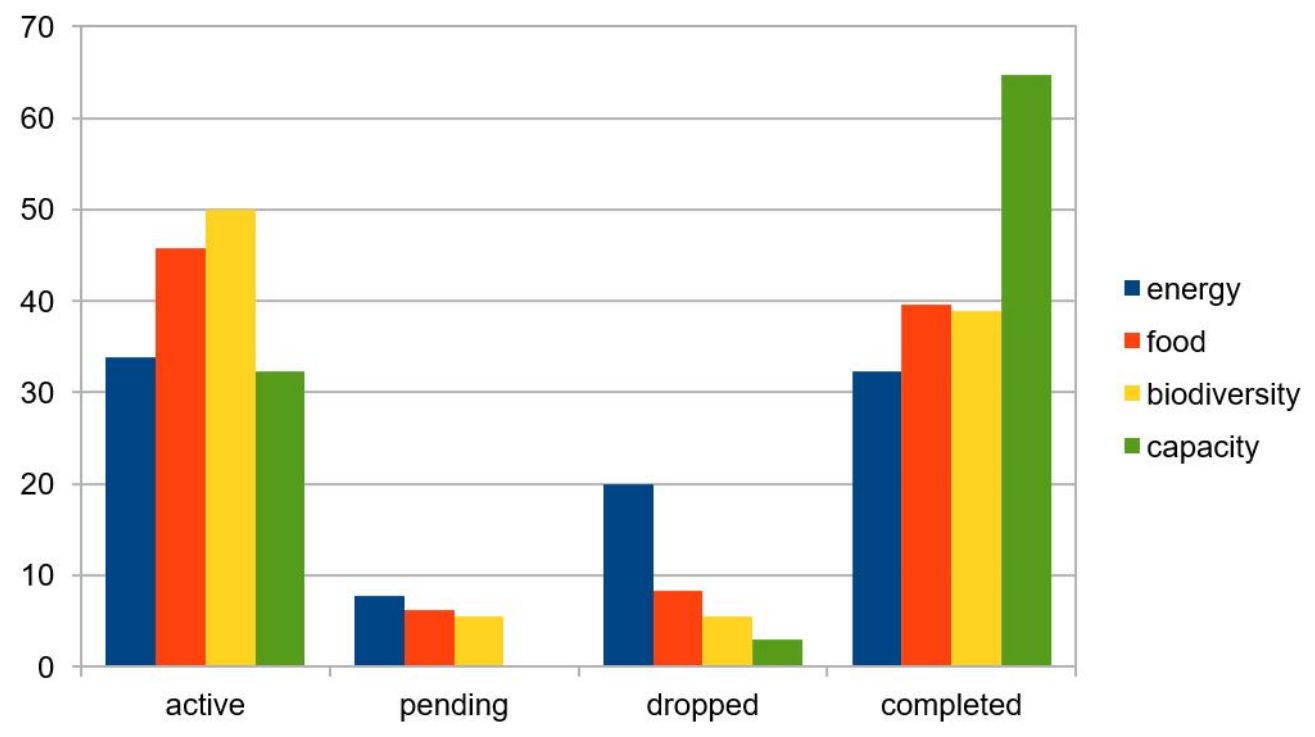

Source: authors' own elaboration.

In considering the Project activities overall, the majority (39\%) of the work has been in the energy-related domain which has also been, overall, the least successful of the four domains and reflects the majority of those activities that were not completed or dropped because they were seen to be unviable. This may be partly attributable to the complex technological nature of the activity, and the policy environment within which it must operate.

The second most common Project activities were food-related (29\%) which, when compared with energy, were considered to be more successful with a higher rate of completion and fewer activities deemed unviable. This may partly reflect the less complex and technological nature of the activity and the more permissive policy environment within which the activities take place, especially in contrast to the energy-related activities.

Capacity building (21\% of activities), was widely regarded as having been the most successful activity area and the most likely to reach completion. This theme included a range of specific activities, from the purchase of kit, such as gazebos to loan out to other organisations, through to staff training and the recruitment of volunteers. Moreover, many of the energy, food and biodiversity-related activities 


\section{Andrew MITCHELL, Mark LEMON, Gavin FLETCHER}

were also recognised to have a significant capacity-building component to them. For example, as summarised in Table 1, energy-related activities included a significant amount (83\%) of capacity-building, $77 \%$ of food-related activities also included a capacity-building element, and $61 \%$ of biodiversity-related activities involved capacity-building.

Activities related to biodiversity not only include work on the "buzzing borders" indicator, which quantified the number of areas of specified dimensions planted with pollinator-attracting flowers, but also community gardening work. While comparatively few in number (11\% of all activities), most are still active and have been deemed a success by the team. Of those that were dropped, the "Incredible Edible" scheme was not taken forward following extended delays by the district council in reaching a decision about support, which left inadequate time to effectively engage the scheme with the Harborough communities.

\subsection{Stakeholder survey}

A link to an on-line, anonymous survey was sent to 63 named stakeholders ${ }^{3}$ who had participated in the Project in some capacity and was completed by 47 stakeholders $(75 \%)$. The responses suggest that the position taken by the Project team about the relative success of the SHP activities was broadly supported by the majority of stakeholders. Like the Project team, stakeholders overwhelmingly identified food-related activities to the most successful, while energy-related work was frequently seen as the most challenging. This was commonly attributed to the volatile policy environment and the lacklustre support for renewables by the UK government, as well as changes in tariff rates. In addition, several seemingly viable prospects for roof rental arrangements, as sites for solar PV installations, could not be realised, thereby raising issues of expectation management and exacerbating the difficulty in assessing the impact of policy and economic contexts on these failures.

In their response to on-line survey questions asking for project activities to be ranked, stakeholders identified food-related and capacity-building activities to be the most successful.

\footnotetext{
${ }^{3}$ Stakeholders were identified by the Project team in a facilitated brainstorming session and selected on the basis that they would be the most knowledgeable about the work of the Project.
} 
Table 3. Successes across activity themes as reported by stakeholders via survey

\begin{tabular}{|c|c|c|c|c|}
\hline $\begin{array}{l}\text { Rating } \\
\text { Frequency }\end{array}$ & Very Successful & Quite Successful & $\begin{array}{l}\text { Required Some } \\
\text { Improvement }\end{array}$ & $\begin{array}{c}\text { Required } \\
\text { Significant } \\
\text { Improvement }\end{array}$ \\
\hline \multirow[t]{4}{*}{ High } & $\begin{array}{ll}\text { - Waterloo } \\
\text { Community } \\
\text { Garden }\end{array}$ & $\begin{array}{ll}\text { - } & \text { edibLe16 } \\
\text { - } & \text { Networking } \\
\text { opportunities }\end{array}$ & - $\quad$ edibLE16 & - $\quad$ edibLE16 \\
\hline & $\begin{array}{ll}\text { - } & \text { Local Food \& } \\
& \text { Drink Map } \\
\text { - } & \text { Newsletters \& } \\
\text { communications }\end{array}$ & 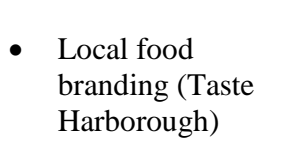 & $\begin{array}{l}\text { - Public home } \\
\text { energy } \\
\text { efficiency } \\
\text { workshops }\end{array}$ & \\
\hline & $\begin{array}{l}\text { - The "I Love } \\
\text { Market } \\
\text { Harborough" } \\
\text { festival } \\
\text { - Networking } \\
\text { opportunities }\end{array}$ & $\begin{array}{l}\text { - The "I Love } \\
\text { Market } \\
\text { Harborough" } \\
\text { festival }\end{array}$ & $\begin{array}{l}\text { Bulk buying } \\
\text { energy \& water } \\
\text { basket scheme }\end{array}$ & \\
\hline & $\begin{array}{l}\text { Opportunities for } \\
\text { volunteers }\end{array}$ & $\begin{array}{l}\text { - Raising public } \\
\text { awareness about } \\
\text { local food and } \\
\text { drink in Market } \\
\text { Harborough } \\
\text { Newsletters \& } \\
\text { communications }\end{array}$ & & \\
\hline Low & $\begin{array}{l}\text { Raising public } \\
\text { awareness about } \\
\text { local food and } \\
\text { drink in Market } \\
\text { Harborough } \\
\text { - Arts Fresco food } \\
\text { area }\end{array}$ & $\begin{array}{ll}\text { - } & \text { Opportunities for } \\
\text { volunteers } \\
\text { - } & \text { Green Open } \\
\text { Homes } \\
\text { - } & \text { Local Food \& } \\
\text { Drink Map } \\
\text { - } & \text { Food Forum } \\
& \text { Steering Group }\end{array}$ & & \\
\hline
\end{tabular}

Source: authors' own elaboration.

Table 3 summarises how stakeholders ranked the success of each Project activity using a five-point Likert scale 4 , from "Very successful" to "Required significant improvement". This covered all of the main activities undertaken by the Project pursuant to the funded objectives summarised in Table 1. As can be seen in Table 3, only one of the activities was thought to have "required significant

\footnotetext{
${ }^{4}$ The neutral response of "No opinion/ Don't know" has been excluded for this ranking.
} 


\section{Andrew MITCHELL, Mark LEMON, Gavin FLETCHER}

improvement", whereas the majority appear to have been regarded by survey respondents as either "very" or "quite successful".

From Table 3, it is apparent that overall respondents considered the Waterloo Community Garden to be the most successful of all of the activities, followed by a tie between the Local Food and Drink Map and the Project's Newsletters and Communications activities. On the other hand, respondents generally saw the on-line retailer of local food and drink, edibLE16, as requiring the most improvement. That edibLE16 has been ranked as the highest across three orders of success suggests that the impression it generates is contentious.

In addition to questions concerning the perceived success of specific activities, a further set of nine questions asked respondents to rate the degree of impact a given activity was thought to have had on a baseline condition, and further asked respondents to elaborate on their selection using an open text response field.

Table 4 summarises how stakeholders rated the impacts on these parameters. It will be noted that the "Cannot say" option was selected the most frequently by survey respondents. This may be due to several reasons. First, because the impact of the Project on addressing fuel poverty ${ }^{5}$ and improving the energy efficiency of SMEs are less likely to be visible to those not directly engaged in those activity streams. Such activities do not generally manifest in observable changes unless one is somehow involved in those domains.

The second reason for a high number of "Cannot say" responses may also be attributed to the low degree of cross-over among respondents who are involved in the energy-related activity streams and those in the food-related streams. Those who are involved in one stream are less likely to be able to comment on the impacts of activities in a second stream.

Finally, the notion of "impact" implies change with respect to a given baseline. Where respondents are not familiar with baseline conditions, they may not feel qualified to comment on the degree of changes that may be attributed to a given

\footnotetext{
5 "Fuel poverty in England is measured using the Low Income High Costs (LIHC) indicator. Under the LIHC indicator, a household is considered to be fuel poor if: they have required fuel costs that are above average (the national median level) and were they to spend that amount, they would be left with a residual income below the official poverty line" https://www.gov.uk/government/collections/fuelpoverty-statistics [01.02.2018].
} 
activity stream. On reflection, the use of the word "impact" in a broad-based stakeholder survey may constrain the granularity of the responses, and perhaps should be reserved for use with domain specialists who will be able to offer a more informed response.

In Table 4, the values in each cell refer to the number of responses that rated a field according to one of the Likert options. For example, one respondent rated "Improving domestic energy efficiency" as a "significant" impact of the Project's activities, whereas a majority either thought that it had "some" impact or felt that they "cannot say".

Table 4. Stakeholder ratings of the impact of Project activities

\begin{tabular}{|c|c|c|c|c|c|c|}
\hline & Significant & Noticeable & Some & Negligible & None & Cannot say \\
\hline $\begin{array}{l}\text { Improving domestic } \\
\text { energy efficiency }\end{array}$ & 1 & 0 & 20 & 5 & 1 & 20 \\
\hline $\begin{array}{l}\text { Improving SME } \\
\text { business energy } \\
\text { efficiency }\end{array}$ & 0 & 6 & 13 & 1 & 0 & 27 \\
\hline $\begin{array}{l}\text { Reduce Greenhouse } \\
\text { gases }\end{array}$ & 1 & 2 & 16 & 5 & 2 & 21 \\
\hline $\begin{array}{l}\text { Supporting local food } \\
\text { producers }\end{array}$ & 17 & 19 & 1 & 0 & 0 & 10 \\
\hline $\begin{array}{l}\text { Supporting local food } \\
\text { retailers }\end{array}$ & 11 & 18 & 5 & 1 & 0 & 12 \\
\hline $\begin{array}{l}\text { Addressing fuel } \\
\text { poverty }\end{array}$ & 0 & 1 & 7 & 5 & 4 & 30 \\
\hline Improving biodiversity & 1 & 4 & 17 & 4 & 0 & 21 \\
\hline $\begin{array}{l}\text { Encouraging growing } \\
\text { own food }\end{array}$ & 5 & 13 & 17 & 1 & 0 & 11 \\
\hline $\begin{array}{l}\text { Contribution to overall } \\
\text { sustainability }\end{array}$ & 4 & 13 & 18 & 1 & 0 & 11 \\
\hline Totals (\%) & 9.5 & 18 & 27 & 5.4 & 1.7 & 38.5 \\
\hline
\end{tabular}

Source: authors' own elaboration. 
From Table 4, it is evident that overall respondents rated activities to have had, at least, "some" impact (27\%), while the second most frequent option selected suggested that respondents thought that the project activities exerted "noticeable" impacts (18\%). It is also apparent that respondents rated the food-related activities supporting local food producers and supporting local food retailers - as having had the most impact overall. Those activities considered to have had negligible impacts appear to concern energy-related interventions, specifically domestic energy efficiency, reducing greenhouse gases, and addressing fuel poverty. As noted above, this may be partly attributable to the lack of visibility of such activities to those outside of that domain.

Two further analyses were undertaken of the open text responses from stakeholders participating in the survey. The first was to mine the open text responses to identify frequently used terms. Term use frequency is taken as a measure reflecting the significance or salience of those terms for respondents (Hahn, Mani 2000; Laver et al. 2003; Hillard et al. 2007; Grimmer, Stewart 2013). The second maps the open text survey responses to a sentiment analysis which yields insight into the attitudes or affective opinions of the stakeholders' responses to questions about the Project's work.

The frequency of words used by stakeholders in responding to the survey are shown as a "word cloud" diagram in Figure 3. Larger text correspond to higher use frequencies, suggesting that these terms are the more salient for respondents. 
Figure 3. Survey responses overall - Word frequency

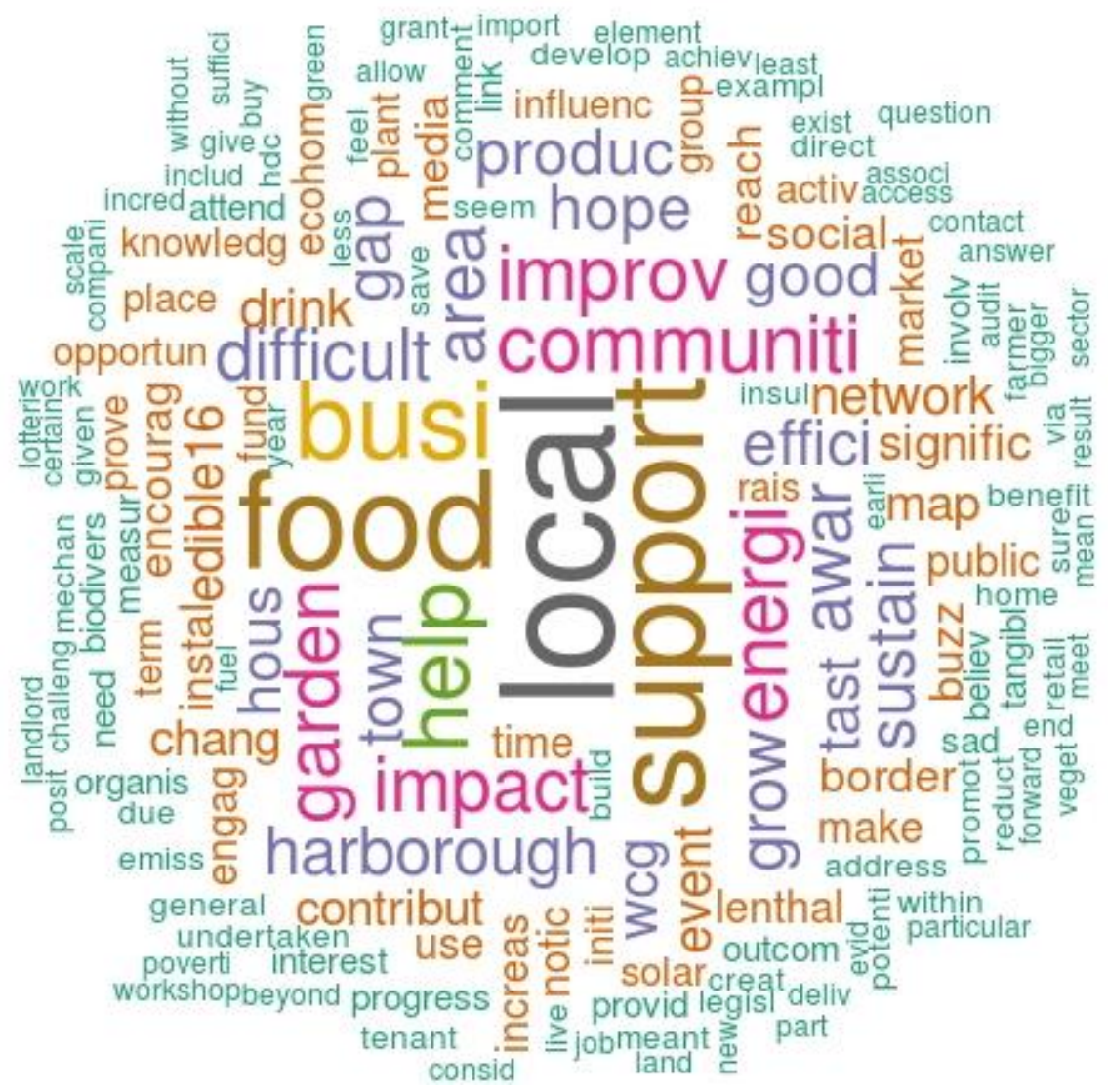

Source: authors' own elaboration.

The terms "local", "food" and "support" appear to sum up the contribution of the Project from the respondents' perspective and substantiate the impact ratings given in Table 3.

The contribution of the Project to the energy ("energi") agenda may be less pronounced in comparison to the food agenda, but is cited as frequently as are "impact", "improv" (improve, improvements) "communiti" (community), and "garden". Together, these words seem to provide a synopsis of those areas within

\footnotetext{
${ }^{6}$ Due to the use of stemming, words are shortened to their respective lemmas.
} 
which the Project made a contribution to Market Harborough from the perspective of the survey respondents.

To obtain insight into the mood underlying the responses, a second type of analysis was undertaken and summarised in a sentiment analytic graph. Figure 5. illustrates the general opinion or attitude of respondents through the words they chose in response to the open text questions. These responses are mapped on to the NRC Lexicon which associates words with eight emotional attitudes (Saif et al. 2012; Mohammad, Turney 2013; Jockers 2017).

\section{Figure 4. Sentiment analysis of survey responses}

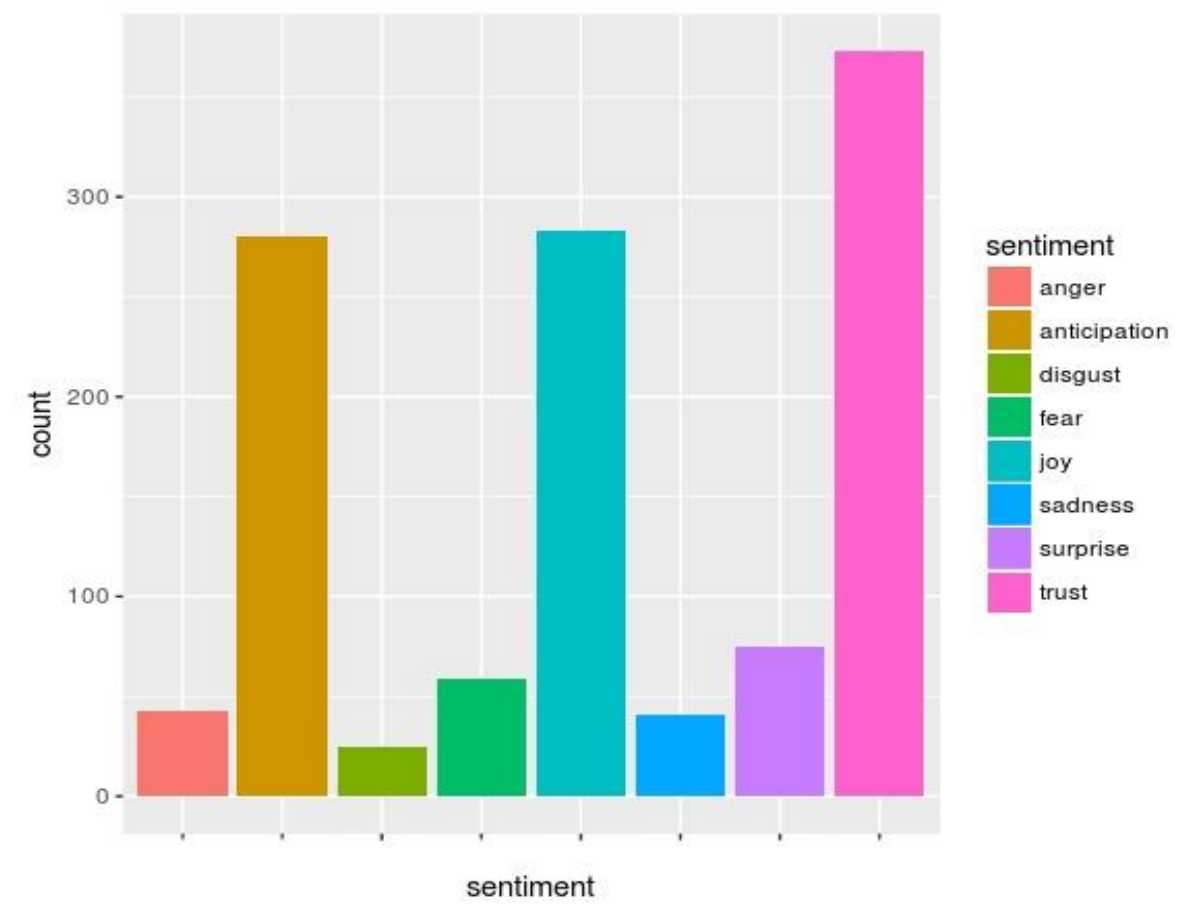

Source: authors' own elaboration.

The sentiment analysis suggests the overall mood, or emotional tone, of respondents to the survey questions expressed through their responses, and helps to 
dig a bit deeper into the emotional valency of how the respondents were disposed with respect to answering the questions.

Trust, in Figure 5, may be indicative of goodwill and social capital (Putnam 2000; Maurer et al. 2011) and its high value interpreted as being a positive opinion among the respondents. This is further supported by the elevated parameters of "Joy" and "Anticipation" which are again both positively charged feelings that suggest participants responded positively overall to the Project.

The negatively charged emotional dimensions, such as "Fear" and "Surprise" (i.e., uncertainty), are slightly elevated, but these are comparatively low and attenuated, and overshadowed by the more significant positive emotions. When all of the open text responses are combined, the mood of the respondents tends to be generally positive - the analysis graphs high levels of trust especially, suggesting a solid reserve of social capital garnered by the Project.

\subsection{Focus groups}

The third data collection method in this lessons learned evaluation employed the focus group format with a cross section of 30 stakeholders, partners, and representatives from other involved groups. The responses from each of the four focus groups were transcribed from the audio recording and then analysed statistically for word use frequency and the strength of correlation among different frequently used words. As observed above, the assumption is that respondents will use words that reflect what is important to them in the course of conversation (Hahn, Mani 2000; Laver et al. 2003; Hillard et al. 2007; Grimmer, Stewart, 2013), and this becomes a computationally replicable means with which to identify topic salience in conversation transcripts.

In common with the findings from the stakeholder survey, the "food" activity is referenced most frequently, within the next most frequently occurring word context of "local" and "involv" (the stemmed term for words such as involve, involved, and involvement, etc.), and "busi" (business and so on). In the context of the word "food", the most frequently associated terms food occurs with are "local" (a correlation of 0.71 ) and "map" (a correlation of 0.56). This isn't really surprising 
since most of the time, participants, when speaking of food, would specifically state "local food", and also commonly included references to the food and drink map.

\section{Figure 5. Focus group - All responses}

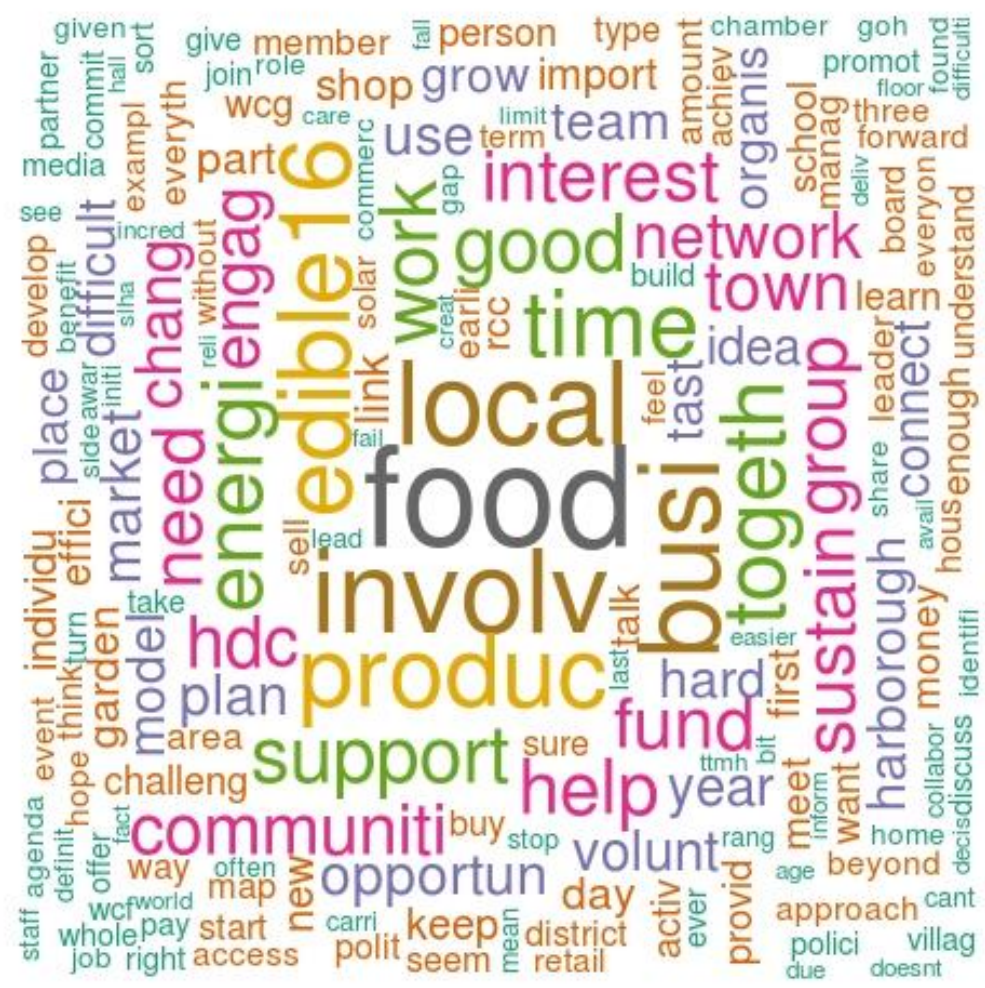

Source: authors' own elaboration.

If food was the most frequently discussed activity, edibLE16 and the relationship with producers were the third most frequently discussed aspects of the Project's work, with "energi" (as pertaining to energy and its variants) among the fourth most frequently discussed aspects, along with "support", "work", "good", "time" and "together". The reference to "time" may also reflect a pattern that emerged from each focus group where participants responded to the opening question concerning the key lessons learnt over the life of the Project by observing the time lag in getting activities started and up and running. 
Relatively few references are made to partner institutions. This may reflect how these institutional actors have been seen as playing small or low profile roles in the work of the Project and its different activities, at least from the perspective of the focus group participants.

When the sentiment analysis, or opinions, of the participants' responses are taken overall, the mood appears to be positive.

\section{Figure 7. Focus group - Sentiment analysis of all responses}

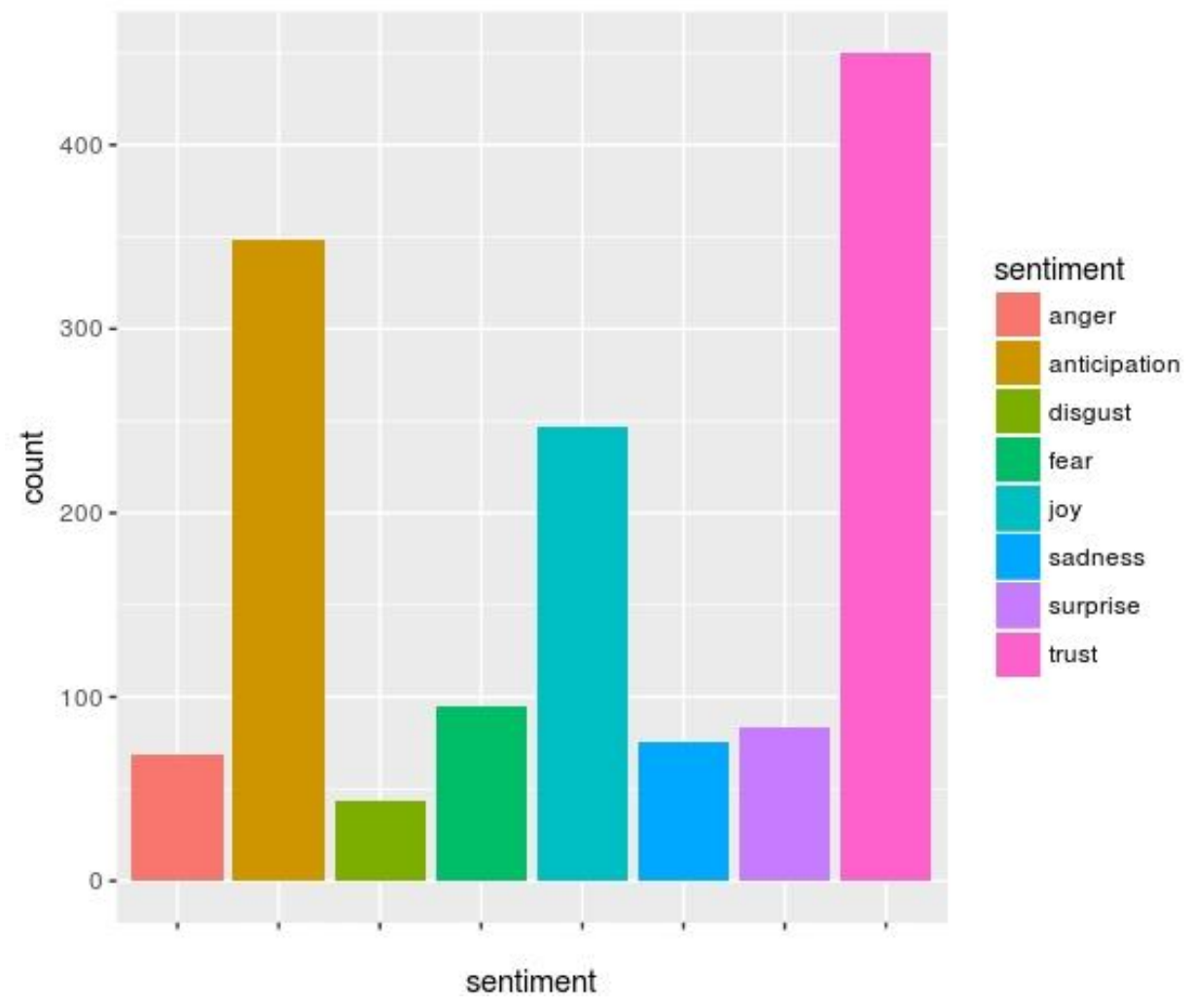

Source: authors' own elaboration. 


\section{Andrew MITCHELL, Mark LEMON, Gavin FLETCHER}

Levels of trust are high, and as discussed in the previous section, this may be indicative of social capital generated among participants. The level of anticipation is high, indicating a sense of optimism, and joy is also elevated, suggesting overall satisfaction among the stakeholders. These results are consistent with those found in the sentiment analysis of the on-line survey open text responses.

The contribution of these computational analyses to a lessons learned evaluation is two-fold. First, because the algorithms used are open source and transparent, the methods employed here are replicable which facilitates increased confidence in the validity and verifiability of the findings. Given access to the same data set, the findings can be confirmed, and using the same methods, different data sets can be compared. Together, this methodological standardisation introduces a degree of rigour to the evaluative process that is otherwise lacking when the analysis depends on the interpretation offered by the evaluator alone.

Second, the computational analyses have facilitated insights into both the survey and the focus group data with respect to topic salience and affective loading that may not have otherwise been possible to access. By enabling additional perspectives to be brought to bear on the interpretation of data, the overall calibre and comprehensiveness of the analysis are enhanced.

When coupled with analytic transparency and replicability, this suggests that computational approaches offer a potentially significant contribution to the evaluator's methodological tool kit. However, on their own, computational methods are not sufficient, and for this reason we also incorporated the qualitative method of thematic analysis, as discussed in the next section.

\subsection{Thematic analysis}

As noted earlier, a thematic analysis is an iterative process of reviewing textual data and identifying recurring patterns - themes - which occur at different points across the data set. The emergence of these patterns in the form of words, associations, and meanings are considered for their contribution to telling the story of how participant stakeholders engage with and make meaning about the Project and its different activities. As such, it is a qualitative method, which counterbalances the computational methods of text mining and sentiment analysis, and was 
employed to obtain an alternate perspective on how stakeholders made sense of the Project's activities.

Six themes were identified as follows: Milieu, Engagement, Networking, Governance, Outcomes, and Learning. Each was in turn comprised of a series of sub-themes.

Each theme is a narrative about the practical experiences of delivering a funded project within a given socio-political context. For example, the theme of "Milieu" identifies the influences of how the project is supported by local leaders, the time lag in getting things going, the challenges of changing habits, and how macro-economic and policy volatility has local micro-impacts. The theme of "Engagement" concerns the reach of the Project's work and communications strategy, the receptivity to the Project by local people, and how well the Project's own objectives feed into local priorities. The narrative accounts that concern the Project's "Networking" activities position the Project as a catalyst of new opportunities, converging groups around points of common interest and enabling participants to realise their ambitions.

Some of the focus group discussions concerned "Governance", particularly the processes of decision-making, how opportunities were negotiated and the Project's strategising to achieve its objectives. The mechanisms for meeting these were clustered under the theme "Outcomes" and impacts, i.e. what worked well, and what required improvement. Finally, the thematic of "Learning" details the narratives that reflect on what might be done differently in any future iterations of the Project and also what was learned overall from the experience of being involved with doing the Project. These are summarised in Table 5, below. 


\begin{tabular}{|c|c|c|c|c|c|c|c|c|c|c|c|c|c|c|c|c|c|}
\hline & 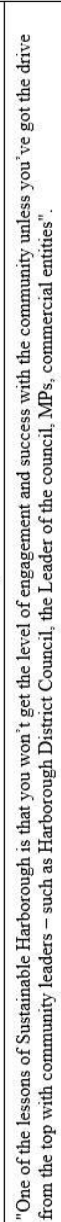 & 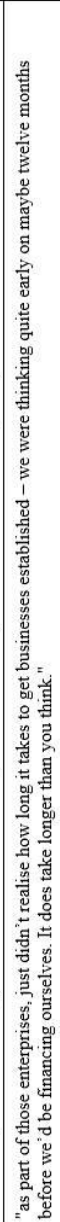 & 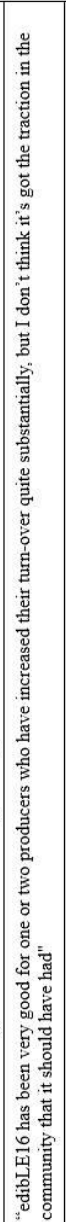 & 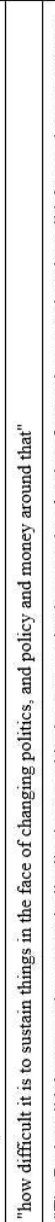 & 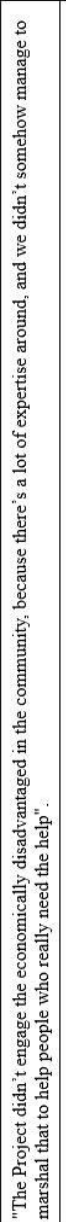 & 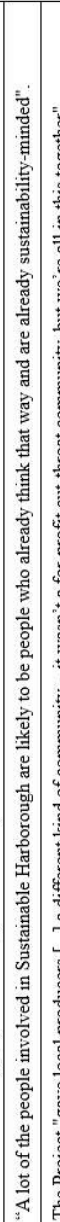 & 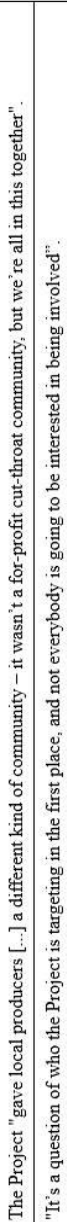 & 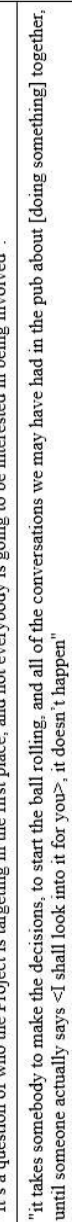 & 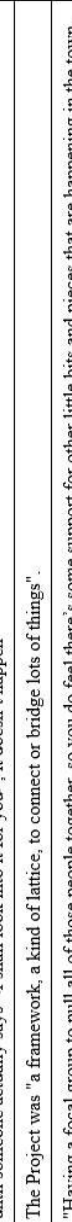 & 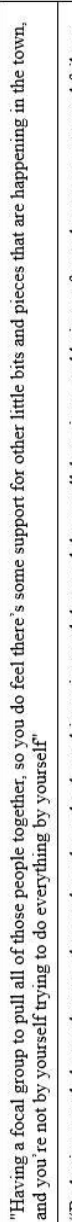 & 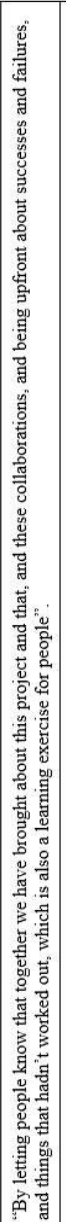 & 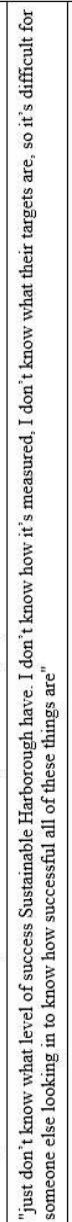 & 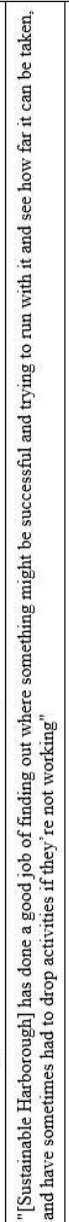 & 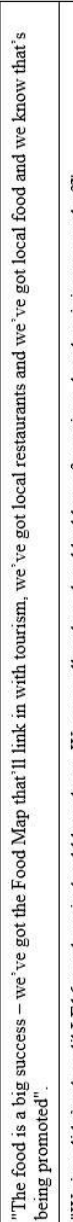 & 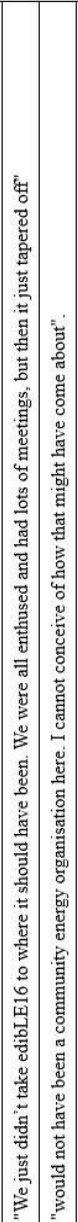 & 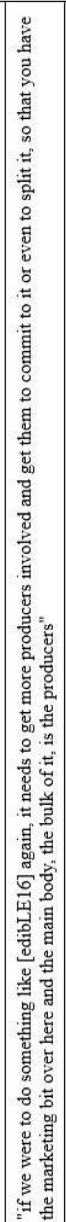 & 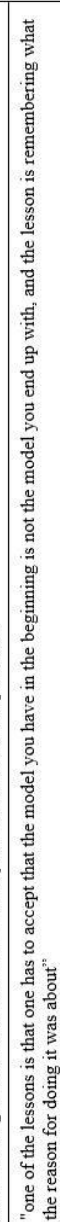 \\
\hline & 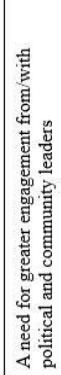 & 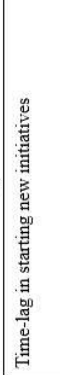 & 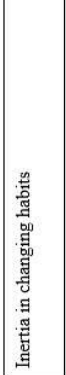 & 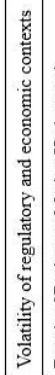 & 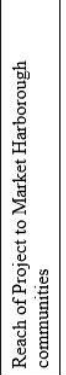 & 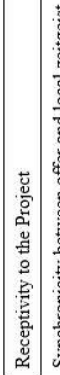 & 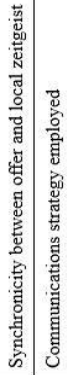 & 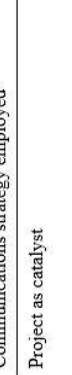 & 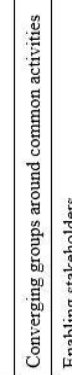 & 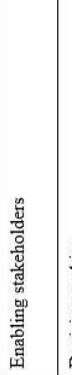 & 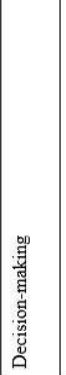 & 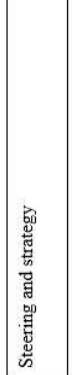 & 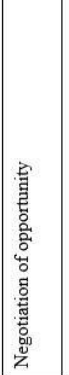 & & 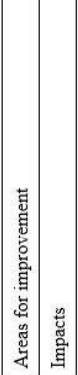 & 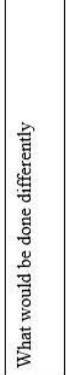 & $\begin{array}{l}\vec{m} \\
\vec{E} \\
\vec{E}\end{array}$ \\
\hline & & $\frac{\vec{z}}{\vec{z}}$ & & & & & & & & & & & & & & & \\
\hline
\end{tabular}


The quotes cited above have been selected because they represent the impetus of each sub-theme. What is of interest here is when the thematic analysis, and the supporting quotes, are read alongside the word frequency analysis, a coherent account of the focus group conversations is generated. The word frequency analysis gives a statistical representation of the dominant - as in most frequently discussed concerns of the focus groups, while the thematic analysis yielded a qualitative reflection of what focus group participants seemed to mean when voicing their concerns and opinions.

\subsection{Triangulation}

Triangulation is a means by which the findings of an evaluation are checked for credibility. Here, this process concerns less a confirmation of unchanging phenomena but more the verification of the constructs offered by stakeholders and the interpretation thereof from the perspective of the actors involved (Guba, Lincoln 1989; Patton 2001).

There were three points during the course of the evaluation that triangulation meetings were scheduled. The first followed the initial scoping meeting, and involved a confirmation of the information provided by the Project staff team in terms of scope, accuracy, and interpretation, and also to use the staff team as consultants on developing the survey questions.

The second triangulation meeting was held a few months later following the analysis of both the survey and focus group data collection processes. At this meeting, the results from the text mining, sentiment and thematic analyses were presented to the Project staff team. The methodology was introduced and explained, and feedback was elicited with respect to both content and presentation.

The final meeting was a presentation given to the Project team and Partnership Board by the lead author on the final report, where the method and findings were discussed, along with the implications arising from the lessons.

These triangulation meetings not only maintained transparency and accountability, but ensured that the final report would be of utility for the commissioning Project (Patton 1997). 


\section{Reflections on the methodology}

This paper began by acknowledging that there is little in the way of good practice guidance for the methods by which an evaluation of the lessons learned by a project are to be captured, analysed, and interpreted. In effect, the extant literature on good practice for conducting a lessons learned project evaluation may be distilled to the advice of McClory et al., (2017: 1322) "to capture the results and experiences from successes, failures and near-misses". However, to date, there remains very little detail on how this objective might be achieved.

Arguably, the emphasis given in the literature to evaluating the lessons learned by a given project remains more closely aligned to a project management perspective, with a focus on objectives, stages, data capture, and a linear delivery common to this discipline. Thomas (2015), for example, restricts his treatment to the process of managing the project of a lessons learned evaluation rather than the actual methodology involved in doing the work.

To address this apparent gap in the literature, we have envisioned a practical methodology for conducting a lessons learned evaluation which would include enhanced consideration of ways with which to identify and engage stakeholders, the facilitation of focused critically reflective conversations, ways for separating the "signal" from the "noise" in terms of topic salience, navigating and reconciling conflicting perspectives, and ways of tracking and bringing to the surface latent meanings and interpretations among stakeholder narratives.

As a consequence, the methodology proposed here is aligned more closely with research than with project management. The methodology described in this paper pays considerably closer attention to what the Project stakeholders identify as being important to focus on, what they deem to have been "successes, failures and nearmisses". As reported in this paper, this was accomplished by engaging the Project team as expert consultants to identify what they thought were the successes and failures, which were contextualised with reference to the delivery status of each activity, and these findings were subsequently triangulated through the on-line survey and focus groups. The Project team were also engaged in identifying stakeholders to be invited to participate in the survey and focus group, and care was 
paid to ensure that these represented a cross-section of the various Project activities, partners, and other relationships that had been key to the Project's evolution.

Given that surveys and focus groups often generate a range of opinions, perspectives, and insights from engaged stakeholders, a strategy was required to parse the volume of data to distinguish "signal" from "noise". The approach adopted here was to use the statistical rigour of text mining, specifically word frequency analysis, and to identify the strength of word associations. This approach yielded key word in context (KWIC) results which were systematically reviewed to identify and isolate what stakeholders thought was salient, across both the open text survey fields and the transcribed focus group discussions. Furthermore, through the use of sentiment analysis, an attempt was made to obtain insight into the affective mood of the respondents with respect to their responses to the survey questions and focus group prompts. The findings from this method yielded an impression that stakeholders held the Project and its activities in high esteem, as portrayed by the elevated scores in the trust parameter, which was interpreted to suggest that the Project had acquired considerable social capital among its stakeholder groups.

\subsection{Critical reflections}

However, text mining, by virtue of its statistical approach, does not generate insights into the latent meanings and narrative threads which permeate human discourse and give human communication its richness. To counterbalance this limitation, the thematic analytic method was employed to bring these latent semantic threads to the foreground. By doing so, we discovered, for example, key insights into how stakeholders themselves located the Project within the broader sociopolitical milieu, identifying the necessity of community and local political leadership as a key ingredient to Project success. As a result, while it may appear obvious, the implication for project design and funding is that these would benefit significantly from locking down such endorsement and support for the project from the outset, both in the spirit of furthering partnership working, but also to bring about greater synergies of purpose. Moreover, important connections were made by stakeholders between the local take up of community-owned energy microgeneration schemes and the broader policy environment of the UK at the time. 


\section{Andrew MITCHELL, Mark LEMON, Gavin FLETCHER}

Again, this demonstrates the importance of a project's context as a determinant of its ultimate success.

A second example concerns the contested value of edibLE16, first mooted in the survey responses (see Table 2), and explored further through the context of the focus group discussions. Although none of the focus group prompts tackled this activity directly, nor even alluded to it, participants themselves addressed this activity from multiple perspectives. By thematically analysing participants' responses, it became apparent that the issue of success or failure is far more nuanced than one might at first think. In the case of edibLE16, for example, what we found was that from the perspective of using market reach and number of customers as a criterion for success, edibLE16 was less than successful.

However, as many participants observed, where edibLE16 was seen as having been very successful was in its provision of a safe, non-competitive space that brought together local food and drink retailers, producers and processors in a way that had never before been accomplished in the area, and which challenged the territorial defensiveness a competitive market tends to engender. This could not have been anticipated at the outset, and raises the important question for a lessons learned evaluation that restricts its focus to "successes, failures and near-misses" as to the criteria by which such judgements are being made. We believe that the methodology used here helped uncover some of the nuanced complexity of projects that a more project managerial approach would be less sensitive to.

The final report tested the findings, and the methodology, through a series of triangulation meetings, initially with the Project staff team, and subsequently with the Partnership Board. In both instances, feedback was invited, and provided, and this process gave the evaluation a "sanity" check with respect to the relevance, validity, and transparency of the findings.

While the methodology described in this paper appears to demonstrate a goodness of fit with this particular evaluation of the lessons learned by the Sustainable Harborough Project, caution is advised in terms of whether such a method is suitable as a one-size-fits-all approach. Clearly, the methodology adopted must be flexible to the nature, context, and scope of the project being evaluated. Some projects will necessarily be more linear, with clear project delivery stages, 
strictly defined objectives and methods for delivery, and perhaps this method will be less suited to such projects. Large civil engineering and IT projects and corporate development projects come to mind as examples. However, unlike such examples, community development projects are unlikely to be so tightly managed and constrained by structured project management and accountability governance regimes.

As a result, the methodology reported on here is likely to be better suited for developmental type of projects, such as the case studied here projects that tend to learn as they go, involve a range of stakeholders, and which are more fundamentally "messy" in nature with stakeholders tending to be more interested in getting things done. This is because the method is adaptive, but more critically, because it locates the process of learning as the creation of new meanings. Consequently, from this perspective, the meanings that the stakeholders generate through the evaluative process are seen here as the most significant factors to emerge from this process and constitute, in effect, the heart of the lessons learned.

This raises more questions than can be answered given constraints of space. For example ${ }^{7}$, if the guidance outlined here amounts more to a research method, it raises the question about how probable it is for smaller-scale projects to attempt this form of evaluation, and whether doing so requires stakeholders to possess specific sets of skills. Not only does this problematise the distinction between research and evaluation, but also reiterates the need for the Project Management Book of Knowledge (PMBOK) literature to specify guidance for practitioners to draw on who may not, themselves, be researchers. This will likely remain a topic for future debate.

\section{Conclusion}

While knowledge and learning are considered organisational assets, the process whereby learning is captured to inform knowledge remains a project evaluation objective that is not well supported by methodological good practice guidance. As a

\footnotetext{
${ }^{7}$ As pointed out by an anonymous reviewer about an earlier draft of this paper.
} 


\section{Andrew MITCHELL, Mark LEMON, Gavin FLETCHER}

result, approaches to these important evaluative practices are diverse leading to variable benefits for the organisation attempting to transform its learning into knowledge. For small-scale community-based development projects which work through a range of stakeholders and often without structured project management frameworks, such as PRINCE2 (OGC 2009), efforts to capture lessons learned are likely to be even more heterogeneous than in projects that do operate with such structured governance standards. This means that a systematic framework and process may be even more important to follow, in order to track change in the same project across time or to contrast different projects at the same time. Such a framework is important for evaluating the learning that emerges from "complex" and continuously changing systems.

Some systematic (and replicable) tools were employed and have been reported in this paper. Specifically, this paper reports on the use of a mixed methods approach to evaluating the lessons learned by the staff team and engaged stakeholders of a case study community development project. The method adopted for this evaluation combined both a statistical analysis of transcribed focus group and survey responses as well as the qualitative thematic analysis of these responses.

The use of text mining for evaluating project learning is an original contribution to this field and was recruited for its statistical potential to bring to the surface those concepts considered salient by the respondents. The emotional tone of the responses was mapped against the NRC Lexicon, which returned significant loading in positive attitudinal affect among respondents with respect to their answers to survey questions and focus group prompts overall.

The treatment of text as a data set, effectively a statistical "bag of words" devoid of meaning, was complemented through a detailed thematic analysis of the transcribed responses. This helps bring to the fore the narrative threads that warp and weave throughout the transcripts, which contextualise and provide richer meanings to what respondents identified as salient learning garnered through their project experiences. 
If projects, such as the case studied here, are construed as sites of experimental intervention in addressing such "wicked problems" (Rittel, Webber 1973) as sustainability, the learning and knowledge acquired over the course of implementing the intervention may be regarded as a potential asset for both present and future projects. By harnessing such knowledge assets, resources are less likely to be diverted towards covering ground that has already been found to be less than productive and can be released for more effective ambitions. However, this may only be achieved if the lessons learned are of a high-quality, in Patton's (2001) sense, as based on robust triangulated evidence. The implication of this is that evaluation of the lessons that projects learn requires evaluators to adopt an approach akin to constructivist informed research (Guba, Lincoln 1989) with an emphasis on a triangulated evidence base linked to the attainment of project outcomes. The present study endeavours to exemplify this guidance.

Nevertheless, it is important to point out that no attempt has been made here to link the learning derived through this project evaluation to the wider literature on grassroot sustainability initiatives. We hope to explore these connections further in a subsequent paper which will devote greater attention to the findings within the context of the grassroots sustainability initiatives literature. The emphasis in the present work has been primarily on the use of a unique four-phase methodological framework as contribution to a perceived gap in the PMBOK good practice guidance on lessons learned evaluation.

Whatever the probative value of the actual findings with respect to the sustainability initiatives literature, the method discussed above represents an attempt to generate and contribute to the discussion about a vital skill set required for the $21^{\text {st }}$ Century. This emphasises the need for learning to be reinvested in organisational development and future project design and funding policies so that hard-won experience, and the lessons acquired as a consequence, may be meaningfully captured, codified and utilised as knowledge assets. Guidance on how to do so effectively and consistently is a gap that needs to be met, especially for smaller-scale community development and sustainability initiatives, in order for

\footnotetext{
${ }^{8}$ Generally, wicked problems are those that have no clear solution or ending point, are contested and resist resolution.
} 


\section{Andrew MITCHELL, Mark LEMON, Gavin FLETCHER}

practitioners, funders, and policy makers to divert limited resources away from continuously re-inventing the wheel and instead to concentrate these into using the learning from what has gone before to break new ground. We hope that through the present paper we have made a modest contribution to that process.

\section{References}

Anbari F.T., Carayannis E.G., Voetsch R.J. (2008), Post-project reviews as a key project management competence, ,Technovation”, vol. 28 no. 10, pp. 633-643.

Argyris C., Schön D. (1978), Organizational learning. A theory of action perspective, Addison-Wesley Publishing Company, Cambridge MA.

Bartsch V., Ebers M., Maurer I. (2013), Learning in project-based organizations. The role of project teams' social capital for overcoming barriers to learning, „International Journal of Project Management”, vol. 31 no. 2, pp. 239-251.

Big Lottery Fund (2012), £12m lifeline for vulnerable facing fuel and food poverty, Big Lottery Fund: News and Events, https://www.biglotteryfund.org.uk/global-content/pressreleases/england/archive/12m-lifeline-for-vulnerable-facing-fuel-and-food-poverty [03.042016].

Boisot M.H. (1999), Knowledge assets. Securing competitive advantage in the information economy, Oxford University Press, New York.

Braun V., Clarke V. (2006), Using thematic analysis in psychology, „Qualitative Research in Psychology", vol. 3 no. 2, pp. 77-101.

Bruner J. (1986), Actual minds, possible worlds, Harvard University Press, Cambridge MA.

Bryman A. (2012), Social research methods, 4th ed., Oxford University Press, New York.

Carrillo P., Ruikar K., Fuller P. (2013), When will we learn? Improving lessons learned practice in construction, „International Journal of Project Management”, vol. 31 no. 4, pp. 567-578.

Davenport T.H., Prusak L. (1998), Working knowledge. How organizations manage what they know, Harvard Business School Press, Boston.

Duffield S.M., Whitty S.J. (2016), Application of the systemic lessons learned knowledge model for organisational learning through projects, „International Journal of Project Management", vol. 34 no. 7, pp. 1280-1293. 
Feinerer I., Hornik K. (2014), tm: Text Mining Package, http://cran.r-project.org/package=tm [02.11.2018].

Feinerer I., Hornik K., Meyer D. (2008), Text mining infrastructure in R', ,Journal Of Statistical Software", vol. 25 no. 5, pp. 1-54.

Grimmer J., Stewart B.M. (2013), Text as data. The promise and pitfalls of automatic content analysis methods for political texts', „Political Analysis”, https://web.stanford.edu/ jgrimmer/tad2.pdf [02.11.2018].

Guba E.G., Lincoln Y.S. (1989), Fourth generation evaluation, Sage, Newbury Park, CA.

Hahn U., Mani I. (2000), The challenges of automatic summarization, „Computer”, vol. 33 no. 11, pp. 29-36.

Hillard D., Purpura S, Wilkerson J. (2007), Computer-assisted topic classification for mixedmethods social science research, „Journal of Information Technology \& Politics”, vol. 4 no. 4, pp. 31-46.

Jockers M. (2017), Package "syuzhet". Extracts sentiment and sentiment-derived plot arcs from text, https://cran.r-project.org/web/packages/syuzhet/syuzhet.pdf [03.11.2018].

Kayser V., Blind K. (2017), Extending the knowledge base of foresight. The contribution of text mining, „,Technological Forecasting \& Social Change”, vol. 116 no. C, pp. 208-215.

Kumar B.S., Ravi V. (2016), A survey of the applications of text mining in financial domain, „Knowledge-Based Systems”, vol. 114 no. C, pp. 128-147.

Laver M., Benoit K., Garry J. (2003), Extracting policy positions from political texts using words as data, „The American Political Science Review”, vol. 97 no. 2, pp. 311-331.

Levitt B., March J.G. (1988), Organizational learning, „Annual Review of Sociology”, vol. 14, pp. 319-340.

Lindner F., Wald A. (2011), Success factors of knowledge management in temporary organizations, „International Journal of Project Management”, vol. 29 no. 7, pp. 877-888.

Love P.E.D., Teo P., Davidson M., Cumming S., Morrison J. (2016), Building absorptive capacity in an alliance. Process improvement through lessons learned, „International Journal of Project Management", vol. 34 no. 7, pp. 1123-1137.

Makrakis V., Kostoulas-Makrakis N. (2016), Bridging the qualitative - quantitative divide. Experiences from conducting a mixed methods evaluation in the RUCAS programme, „Evaluation and Program Planning”, vol. 54, pp. 144-151. 


\section{Andrew MITCHELL, Mark LEMON, Gavin FLETCHER}

Maurer I., Bartsch V., Ebers M. (2011), The value of intra-organizational social capital. How it fosters knowledge transfer, innovation performance, and growth, „Organization Studies”, vol. 32 no. 2 , pp. $157-185$.

McClory S., Read M., Labib A. (2017), Conceptualising the lessons-learned process in project management. Towards a triple-loop learning framework, „International Journal of Project Management", vol. 35 no. 7, pp. 1322-1335.

Meaney C., Moineddin R., Voruganti T., Ann M., Brien O., Krueger P., Sullivan F. (2016), Text mining describes the use of statistical and epidemiological methods in published medical research, „Journal of Clinical Epidemiology”, vol. 74, pp. 124-132.

Mohammad S.M., Turney P.D. (2013), Crowdsourcing a word-emotion association lexicon, „Computational Intelligence”, vol. 29 no. 3, pp. 436-465.

Moustaghfir K., Schiuma G. (2013), Knowledge, learning, and innovation. Research and perspectives, „Journal of Knowledge Management”, vol. 17 no. 4, pp. 495-510.

Newton J., Franklin A., Middleton J., Marsden T. (2012), (Re-)negotiating access. The politics of researching skills and knowledge for "sustainable communities”, „Geoforum”, vol. 43 no. 3 , pp. 585-594.

Nonaka I., Takeuchi H. (1995), The knowledge-creating company. How Japanese companies create the dynamics of innovation, Oxford University Press, New York.

Office of Government Commerce (OGC) (2009), Managing successful projects with PRINCE2, TSO (The Stationery Office), London.

Patton M.Q. (1997), Utilization-focused evaluation, 3rd ed., Sage, Thousand Oaks.

Patton M.Q. (2001), Evaluation, knowledge management, best practices, and high quality lessons learned, „American Journal of Evaluation”, vol. 22, pp. 329-336.

Powell J.H., Bradford J.P. (2000), Targeting intelligence gathering in a dynamic competitive environment, „International Journal of Information Management”, vol. 20 no. 3, pp. 181195.

Putnam R.D. (2000), Bowling alone. The collapse and revival of American community, Simon and Schuster, New York.

RCC-L (2012), Project delivery plan. Sustainable Harborough challenge: SRC/1/010428951, Leicester.

R Core Team (2014), R: A language and environment for statistical computing, Foundation for Statistical Computing, Vienna, http://www.r-project.org/ [03.11.2018]. 
Rennie D.L. (2012), Qualitative research as methodical hermeneutics, „Psychological Methods", vol. 17 no. 3, pp. 385-398.

Rittel H.W.J., Webber M.M. (1973), Dilemmas in a general theory of planning, „Policy Sciences", vol. 4 no. 2, pp. 155-169.

Rolstadås A., Tommelein I., Morten Schiefloe P., Ballard G. (2014), Understanding project success through analysis of project management approach, „International Journal of Managing Projects in Business", vol. 7 no. 4, pp. 638-660.

Saif H., He Y., Alani H. (2012), Alleviating data sparsity for Twitter sentiment analysis, „CEUR Workshop Proceedings”, vol. 838, pp. 2-9.

Schein E.H. (1996), Three cultures of management. The key to organizational learning, „Sloan Management Review”, vol. 38 no. 1, pp. 9-20.

Sutcliffe K.M., Weber K. (2003), The high cost of accurate knowledge, „Harvard Business Review", vol. 81 no. 5, pp. 74-82.

Thomas W.H. (2015), The basics of project evaluation and lessons learned, 2nd ed, CRC Press, Boca Raton.

Ur-Rahman N., Harding J.A. (2012), Textual data mining for industrial knowledge management and text classification. A business oriented approach, „Expert Systems With Applications", vol. 39 no. 5, pp. 4729-4739.

Williams T. (2003), Learning from projects, „The Journal of the Operational Research Society", vol. 54, pp. 443-451. 